\title{
The paradox of publication in medicine: the case for a mind shift
}

\author{
C. Dan Johnson ${ }^{1}$
}

Published online: 26 January 2022

(c) The Author(s), under exclusive licence to Springer Science+Business Media, LLC, part of Springer Nature 2022

Keywords Publication $\cdot$ Mindshift $\cdot$ Revisions $\cdot$ Feedback

Several manuscripts cross my desk daily as Editor-in-Chief. Our overarching goal is to build on existing knowledge and advance our scientific understanding and capability. Submitted manuscripts should support this goal. Original manuscripts are rarely accepted without revision. We nearly always have at least two independent reviews of each original research submission. Reviewers are very often generous of their time and expertise, helping to guide the author toward a stronger and more scientifically valid submission.

I can recall many times in my own personal career getting reviews back from a journal requiring revisions and a response to each of the reviewer's individual comments. Sometimes it was a rejection. If a revision was possible, I would at first be glad that I had a chance to get the study published, but soon dread would set in as I considered the many hours of work required to make the necessary changes and responses. I realized that the paper would be improved, but it was toil-plain and simple. Today, from my editorial desk I see it differently. I am so grateful to our reviewers for their insight and meticulous review of all aspects of the manuscripts they are assigned. I know that the scientific integrity of the study and the reputation of the journal is bolstered by their recommendations. I do consider how authors may respond negatively to a long list of items the reviewers want them to consider - just as I did in the past. I suspect many will respond with dread, defeat, and potential humiliation that comes from this feedback.

I would like to suggest a mind shift to those authors who have the same negative response that I did. Consider the value that reviewers freely give to authors, to help them toward academic success. Realize how your own academic brand will be enhanced by publishing a much better paper than you initially submitted. The lessons learned from these

C. Dan Johnson

Johnson.C@mayo.edu

1 Mayo Clinic Arizona, Scottsdale, AZ, USA comments can enhance future study design and manuscript preparation. I have a friend who has told me several times that the best co-authors he ever had were the journal reviews. In other words, he received more useful feedback to improve the manuscript from the reviewers than from his co-investigators. Now that is a mind shift that we should all consider! Welcome the feedback, be grateful for the many useful comments and suggestions, and find ways to learn and improve. Expect them and embrace them.

This mind shift might also extend systematically beyond the individual to their respective investigative teams, institutions, and journals. If investigators are getting their best feedback from journal reviewers, shouldn't the investigative teams change their approach to these manuscripts by offering more in-depth and authentic reviews before the manuscript is sent for publication? Should institutions consider the time and effort required to create and revise these manuscripts by providing more targeted resources and time to the investigator and team? Should journals commit to a minimum level of feedback to authors despite rejection without peer review?

The paradox of publishing (and of life in general) is that feedback (that we often equate to failure) drives long-term success. Viewing negative feedback (revisions or rejections) as opportunities to learn and improve could make a big difference in your life (professional and personal). This publication process of submission and revision is an important learning and growing exercise that propels the willing author (and team) toward higher levels of work and achievement. This mind shift could also help reduce the stress often associated with publication and the potential of burnout. It all seems so simple, but it isn't. We must actively decide how we are going to respond positively to feedback and practice it time and again. Eventually, the practice will lead to automatic behaviors-and a lifelong skill will be inculcated. The dread will be gone, learning will accelerate, and personal growth will soar.

Publisher's Note Springer Nature remains neutral with regard to jurisdictional claims in published maps and institutional affiliations. 